\title{
Associations between cow hygiene, hock injuries, and free stall usage on US dairy farms
}

\author{
J. E. Lombard, ${ }^{, 1}$ C. B. Tucker, $†$ M. A. G. von Keyserlingk, $\ddagger$ C. A. Kopral, ${ }^{*}$ and D. M. Wearył \\ *USDA: Animal and Plant Health Inspection Service: Veterinary Services, Centers for Epidemiology and Animal Health, Fort Collins, \\ CO 80526-8117 \\ †Center for Animal Welfare, Department of Animal Science, University of California-Davis 95616-8521 \\ ‡Animal Welfare Program, 2357 Main Mall, University of British Columbia, Vancouver, BC, Canada V6T $1 Z 4$
}

\begin{abstract}
This cross-sectional study evaluated cow comfort measures in free stall dairies across the United States as part of the National Animal Health Monitoring System's Dairy 2007 study. The study was conducted in 17 states and evaluations were completed between March 5 and September 5, 2007. Assessors recorded hygiene and hock scores, number of cows housed in the pen, the number of cows standing with only the front feet in a stall, standing fully in a stall, and lying in a stall. Facility design measures included bedding type, bedding quantity, stall length and width, presence of a neck rail or brisket locator, and relevant distances from the rear and bed of the stall. Of the 491 operations that completed the cow comfort assessment, 297 had Holstein cows housed in free stalls and were included in this analysis. Negative binomial models were constructed to evaluate the following outcomes: the number of cows that were very dirty, had severe hock injuries, stood with front feet in the stall, stood with all feet in the stall, and were lying in the stall. Hygiene was better on farms that did not tail dock cows compared with those that did (5.7 vs. $8.8 \%$ were dirty) and on farms located in the study's west region compared with those located in the east region (5.2 vs. $9.7 \%$ were dirty). Severe hock injuries were less common on farms in the west than those in the east ( 0.5 vs. $4.1 \%$ ). In addition, severe hock injuries were less common on farms that used dirt as a stall base or sand as bedding compared with farms that did not. A higher percentage of cows was standing with front feet in the stall at higher ambient temperatures (incidence rate ratio $=1.016$ ) and as time since feeding increased (incidence rate ratio $=1.030$ ). A lower percentage of cows were standing with front feet in the stall when the stalls were shorter and when there were fewer cows per stall. Standing fully in a stall was performed by a higher percentage of cows during the summer than
\end{abstract}

Received March 3, 2010.

Accepted May 25, 2010.

${ }^{1}$ Corresponding author: jason.e.lombard@aphis.usda.gov during the spring (13.6 vs. $8.1 \%$ ), when cows were provided free stalls with rubber mats or mattresses, and as the distance from the rear curb to neck rail increased. A higher percentage of cows were lying in a stall when sand bedding was used, when bedding was added more frequently, and during the spring months. Results of this national survey indicate that tail docking provides no benefit to cow hygiene and that stall base and bedding are key factors influencing hock injuries and stall usage on US free stall dairy farms.

Key words: cow comfort, animal welfare, hock injury, lying

\section{INTRODUCTION}

Housing for dairy cows should provide a comfortable place to lie down, be reasonably clean, and be designed and maintained so as not to cause injuries. Although this sounds obvious, some dairy facilities do not meet these criteria. For example, hock injuries are common in some free stall barns, especially those using mattresses. In a survey of 100 farms, Fulwider et al. (2007) reported that more than $80 \%$ of cows housed with mattress bedded stalls had hock lesions, but cows housed on deep-bedded sand stalls or a bedded pack had few or no hock lesions.

The effects of barn design on standing and lying behavior have been the focus of considerable research in recent years. This work shows that cows prefer lying surfaces with more bedding (Tucker and Weary, 2004) and spend more time lying down in well-bedded stalls (Tucker et al., 2009) with dry (Fregonesi et al., 2009), well-maintained (Drissler et al., 2005) bedding. Stall dimensions and configuration influence lying times and have a profound effect on standing inside the stall. For example, cows spend more time standing fully in the stall and less time perching with their front feet on the stall surface when provided stalls that are wider (Tucker et al., 2004) and with the neck rail position higher above the stall surface (Tucker et al., 2005) and further from the rear curb (Fregonesi et al., 2009). In addition, inadequate stall design and stall management increase the risk of lameness (Dippel et al., 2009). 
The design and management of the stall and the lying surface can affect cow hygiene. Cows are more likely to defecate onto the stall surface and are more likely to become soiled with manure when housed with larger stalls, especially those that allow cows to stand fully in the stall (Tucker et al., 2005; Bernardi et al., 2009; Fregonesi et al., 2009). Cow hygiene can vary with bedding type (Fulwider et al., 2007; Norring et al., 2008). One management practice that some producers believe improves cow hygiene is tail docking. This idea has some intuitive appeal: if the tail becomes soiled, it may spread the debris with every swish. Research to date comparing docked and intact cows in free stall housing found no difference in soiling (Tucker et al., 2001; Schreiner and Ruegg, 2002).

For the first time, the National Animal Health Monitoring System (NAHMS) 2007 study included measures of stall use (i.e., perching in the stall, standing fully in stall, and lying down in the stall), hock injuries, and cow hygiene. The survey included assessments of barn features (e.g., stall size and surface, manure handling) and management practices (e.g., bedding frequency, stocking density, tail-docking) predicted to relate to the cow-based measures. The objective was to describe which combination of facility design and management factors best predict lying and standing behavior, cow hygiene, and hock injuries in US dairy herds.

\section{MATERIALS AND METHODS}

\section{Data Collection}

The NAHMS Dairy 2007 study surveyed dairy operations in 17 states representing 2 regions (West: California, Idaho, New Mexico, Texas, Washington; East: Indiana, Iowa, Kentucky, Michigan, Minnesota, Missouri, New York, Ohio, Pennsylvania, Vermont, Virginia, and Wisconsin) representing $79.5 \%$ of dairy operations and $82.5 \%$ of dairy cows in the United States. The first phase included survey responses from 2,194 operations. Eligibility to participate in the second phase was based on having 30 or more milk cows. Of the 1,077 eligible farms, a total of 582 completed second-phase questionnaires, of which a convenience sample of 491 completed the cow comfort facility characteristics assessment. This cross-sectional assessment included an evaluation by veterinary medical officers or animal health technicians of cow hygiene, hock injuries, pen size, stall dimensions, and stall usage. Of the 491 operations, 297 were Holstein herds with cows housed in free stall facilities. New Mexico did not have any herds participate in this assessment. Evaluations were completed between March 5 and September 5, 2007.

\section{Measures}

All data were recorded on a specifically developed assessment form. Assessors were asked to focus on the pen that housed the majority of early-lactation cows because these cows were at the highest risk for common problems such as lameness and metabolic diseases. To minimize the effect of disruptions associated with feeding and milking that are known to affect cow behavior (DeVries and von Keyserlingk, 2005), assessments were performed between $2 \mathrm{~h}$ after milking and $2 \mathrm{~h}$ before the next milking (Cook et al., 2005). Assessors recorded the number of animals housed in the pen, the number of cows perching (standing with only the front feet in a stall), standing fully (with all 4 feet) in a stall, and lying in a stall. Facility design measures included bedding type, quantity and frequency of bedding, stall length and width, presence of a neck rail or brisket locator, and relevant distances from the rear and bed of the stall. Timing of the assessments was split into those performed in the spring (March, April, and May) and summer (June, July, August, and September).

Hygiene and hock scores were recorded for up to 100 cows from each herd. If more than 100 cows were present, then a convenience sample of 100 cows was scored. Occasionally, more than 100 cows on the operation were scored. Hygiene scores were modified from a 4-point scoring system developed by Cook (2007) (http:// www.vetmed.wisc.edu/dms/fapm/fapmtools/4hygiene/ hygiene.pdf accessed December 2009) to a 3-point scoring system by combining scores of 3 and 4 into a single category. Cows with no manure on their legs, udder, or flank were assigned a score of 1 ; cows with small amounts of manure on the legs, udder, or flanks were assigned a score of 2 ; and cows with large amounts of manure were assigned a score of 3. A 3-point scoring system developed by Cornell University (http://www. ansci.cornell.edu/prodairy/pdf/hockscore.pdf; accessed December 2009; Hock Assessment for Cattle, Cornell Cooperative Extension, adapted from James Nocek) was used to evaluate hock condition: cows without swelling or hair loss on both hocks were assigned a score of 1 , cows with hocks with hair loss but no swelling were assigned a score of 2 , and cows with hair loss, swelling, or draining lesions were assigned a score of 3 (severe). The location of hock lesions (i.e., tarsal joint or tuber calcis) was not recorded.

Approximately 140 different assessors were used in evaluating the 297 operations. These individuals were trained by coordinators within each state. During the training, the data collectors were given a training video along with color reference cards to use for hock and hygiene scoring and a diagram of free stalls to facilitate 
recording of measurements. The proportion of cows that were tail docked on each of the participating farms was asked of producers during the second phase.

\section{Statistical Analysis}

Five models were constructed to evaluate the outcomes of hygiene scores of 3 , hock scores of 3 , and cows perching, standing fully in the stall, and lying in the stall. The hock and hygiene scores were analyzed by contrasting the most severe outcomes (i.e., hock or hygiene scores of 3) with the lower levels (i.e., scores 1 and 2). Several steps were used to determine which explanatory variables would be included in models. First, explanatory variables that were significant in previously reported studies and others where a plausible biological link could be hypothesized were compiled. These variables are listed in Tables 1 and 2 and primarily relate to specific facility characteristics, region, season, temperature, and time since or until feeding and milking. Second, explanatory variables that were associated with the outcome variables (Table 3 ) with a $P \leq$ 0.10 using negative binomial models constructed using PROC GENMOD in SAS (SAS Institute Inc., Cary, NC) were eligible for inclusion in the respective multivariable model. All eligible continuous and categorical variables were evaluated for correlation using Spearman rank correlation and Kendall's tau, respectively. Finally, negative binomial models were constructed for the multivariable analysis because evaluation of the counts of the outcome variables revealed both overand underdispersion. To take into account the effect of the number of cows on each farm, the log of the total numbers of cows scored for hygiene, hocks, and number of cows in the pen at the time of behavioral assessment were used as an offset variable (denominator) in each respective model. Stepwise backward elimination procedures were used to construct the final models, which included variables with a chi-squared $P<0.05$.

Two sets of statistics are reported: 1) incidence rate ratios that compare the level of class variable to the referent, or in the case of continuous variables, the difference in the logs of expected counts associated with a 1-unit change in the measure, and 2) the predicted percentages of cows for each level of each explanatory variable as generated by the least squares means statement. Model fit was evaluated using the dispersion parameter and the Pearson chi-squared value.

\section{RESULTS}

\section{Descriptive Statistics}

The total number of herds and cows represented by each of the outcome variables along with the mean number of cows per herd assessed is given in Table 3. The hygiene of an average of 96 cows per farm and a total of 25,358 cows was scored. Of these, $49 \%$ were scored as 1 (i.e., clean) and $10 \%$ were scored as 3 (i.e., very dirty/soiled). There were 24,825 cows in total and an average of 94 cows/farm scored for hock lesions. Approximately $77 \%$ of these cows had no visible hair loss or lesions (i.e., score $=1$ ) and approximately $3 \%$ received the most severe hock score $($ score $=3$ ).

Lying and standing behaviors were evaluated for 22,006 cows, with an average of 136 cows/farm. Approximately $9 \%$ of cows were standing with the front feet in a stall, $10 \%$ were standing fully in a stall, and $43 \%$ were lying down in a stall at the time of the assessment.

\section{Hygiene Score}

Of the 22 variables evaluated (Tables 1 and 2), only tail docking $(P=0.008)$ and region $(P=0.007)$ were associated with a hygiene score of 3 (severe soiling). Approximately $69 \%$ of operations tail docked at least a portion of their herd; approximately $31 \%$ of farms did not have any cows with docked tails. The majority of the farms evaluated were in the east region (85\%).

Tail docking and region remained in the final model. The model estimated that $8.8 \%$ of cows were highly soiled (i.e., hygiene score $=3$ ) on farms with docked tails compared with just $5.7 \%$ on farms that did not dock (Table 4). A lower percentage of cows on farms in the west region were highly soiled (5.2\%) compared with farms in the east region $(9.7 \%)$.

\section{Hock Injuries}

Of the 16 explanatory variables, 8 were eligible for inclusion in the multivariable model (Tables 1 and 2). Three of these were significant in the final model: stall base, stall bedding type, and region (Table 5). Farms with rubber mats or mattresses as the stall base had a higher percentage of cows with severe hock lesions (i.e., hock score $=3$ ) compared with farms that had dirt as the stall base. The model estimated that $2.3 \%$ of cows on farms using rubber mats or mattresses and $1.8 \%$ of cows on concrete stall bases had severe hock lesions versus less than $1 \%$ on farms using a dirt base. Region was associated with hock lesions. Only $0.5 \%$ of cows on farms in the west region were predicted to have severe lesions compared with $4.1 \%$ of cows in the east region. Sand bedding was associated with the lowest percentage of severe hock scores $(0.7 \%)$ compared with straw, sawdust, or dry or composted manure $(1.9,1.5$, and $2.7 \%$, respectively). 
Table 1. Categorical variables used in the univariate analysis of variables associated with severe soiling, severe hock lesions, and cows perching (i.e., standing with the front feet in the stall), standing fully in the stall, or lying in the stall on US free stall dairy farms

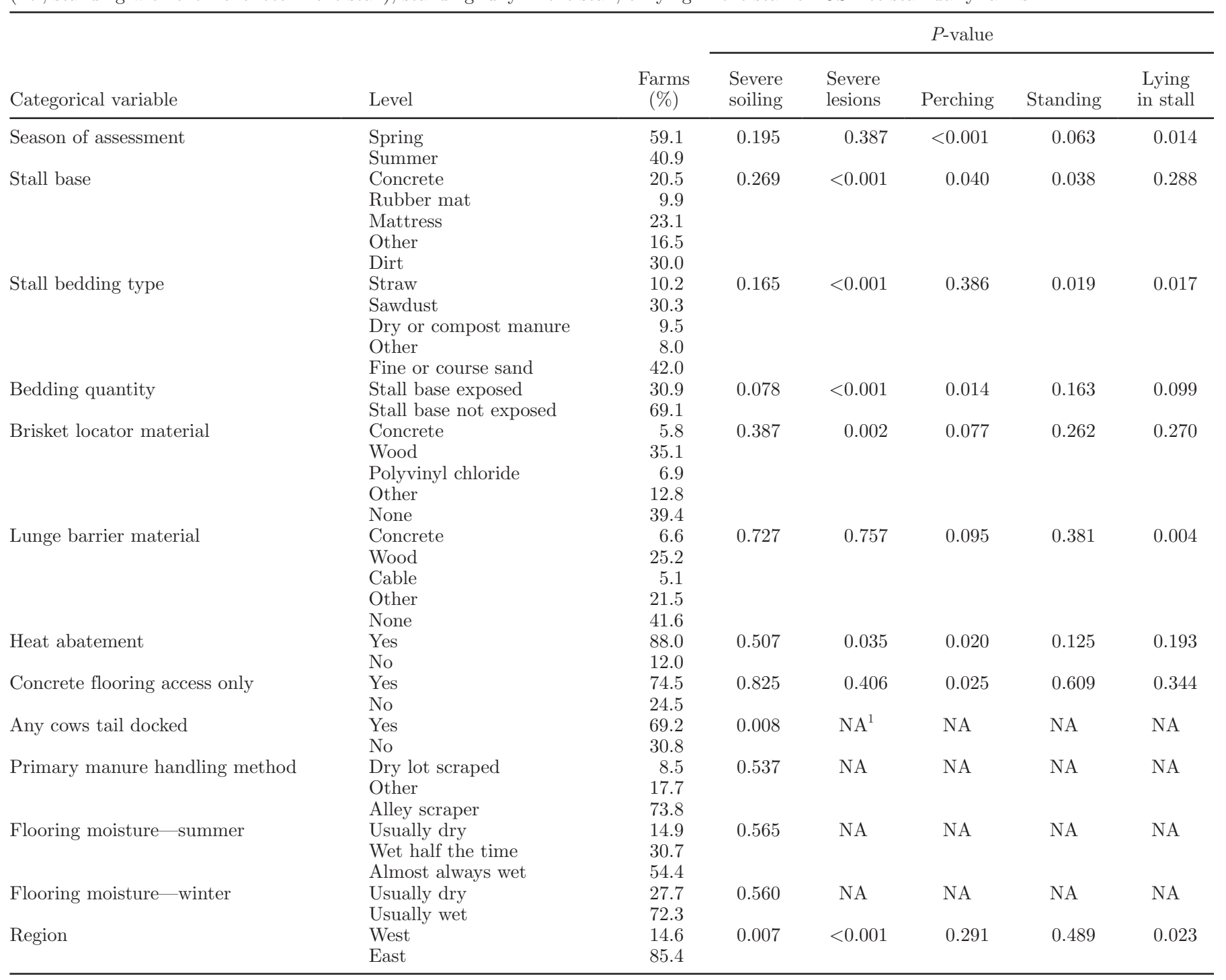

${ }^{1} \mathrm{NA}=$ variable not included in univariate analysis.

Table 2. Mean $\pm \mathrm{SD}$ and $P$-values for continuous variables associated with severe soiling, severe hock lesions, and cows perching (i.e., standing with the front feet in the stall), standing fully in the stall, or lying in the stall on US free stall dairy farms

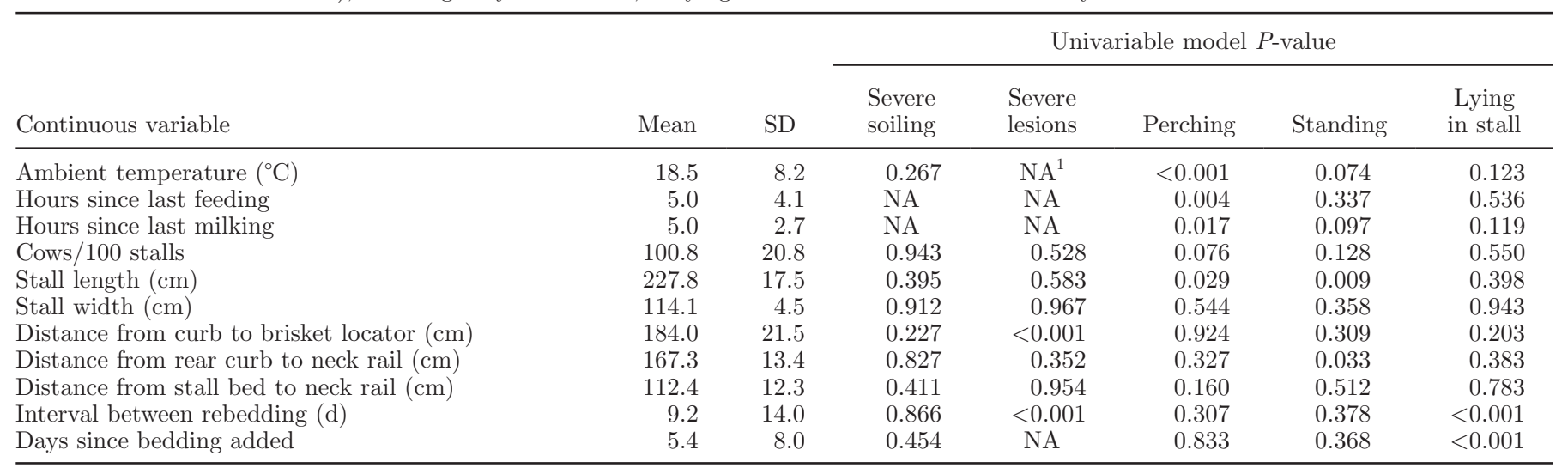

${ }^{1} \mathrm{NA}=$ variable not included in univariate analysis. 
Table 3. Number and mean \pm SD of cows on each farm that were hygiene scored, hock scored, and in the pen on US free stall dairy farms

\begin{tabular}{lcrrr}
\hline Outcome variable & Herds $(\mathrm{n})$ & Cows (n) & Mean & SD \\
\hline Cows hygiene scored & 265 & 25,358 & 95.7 & 64.5 \\
Cows with no soiling (score = 1) & 265 & 12,590 & 48.5 & 30.2 \\
Cows with moderate soiling (score $=2)$ & 265 & 10,175 & 41.4 & 24.1 \\
Cows with severe soiling (score = 3) & 265 & 2,593 & 10.1 & 14.2 \\
Cows hock scored & 265 & 24,825 & 93.7 & 55.3 \\
Cows with no lesions (score = 1) & 265 & 18,880 & 76.5 & 23.7 \\
Cows with moderate lesions (score = 2) & 265 & 5,098 & 20.1 & 20.0 \\
Cows with severe lesions (score = 3) & 265 & 847 & 3.4 & 5.9 \\
Cows in pen & 273 & 22,006 & 136.1 & 112.9 \\
Cows in pen perching in a stall & 267 & 2,912 & 8.5 & 7.0 \\
Cows in pen standing fully in a stall & 267 & 3,365 & 10.3 & 13.6 \\
Cows in pen lying in a stall & 267 & 15,729 & 43.3 & 20.0 \\
\hline
\end{tabular}

\section{Standing with the Front Feet in the Stall (Perching)}

Twelve of the 20 variables were eligible for inclusion in the multivariable model (Tables 1 and 2), and 5 of these variables remained in the final model (Table 6). Farms where the stall base was covered with bedding had more than $9 \%$ of cows perching compared with less than $7 \%$ on farms where the stall base was exposed. Perching increased with ambient temperature and with time since feeding. Perching was less common on farms with longer stalls and higher stocking rates.

\section{Standing Fully in the Stall}

Of the 20 variables evaluated, 3 remained in the final model (Table 7) for standing fully in the stall. Compared with farms with dirt base stalls, farms with rubber mats and mattresses had more cows standing fully in the stall (2.5 and 1.7 times more, respectively). Fewer cows were predicted to stand fully in the stall during the spring (8.1\%) than in the summer (13.6\%). Standing fully in the stall increased as the neck rail placement became less restrictive (i.e., greater distance between the neck rail and curb).

\section{Lying Behavior}

Four of the 20 variables (bedding type, season, presence or type of a lunge barrier, and days since new bedding was added) were significant in the final model (Table 8). Approximately $50 \%$ of cows were lying down on farms using sand bedding compared with $40 \%$ on farms using straw, sawdust, or dry or composted manure. The percentage of cows lying down declined with increasing time since bedding was last added to the stall. A lower percentage of cows were lying down on farms using a wooden lunge barrier compared with those having no lunge barrier. Fewer cows were lying down during the summer compared with the spring (36.7 and $44.0 \%$, respectively).

\section{DISCUSSION}

The 2007 study was the first NAHMS dairy survey to measure animal-based indicators of cow comfort including hygiene, hock injuries, and stall use. This type of assessment is becoming increasingly common in animal agriculture (Fraser, 2006; Mench, 2008) and the current study included measures that were used in dairy assessment schemes in Europe (Capdeville and Veissier, 2001; Main et al., 2003; Ofner et al., 2003; Winckler et al., 2003), the United States (Stull et al., 2005), and Canada (Ito et al., 2009).

Assessments were conducted at a single visit to each farm and there are drawbacks to this limited sampling. Others have found that hock lesions, for example, are not consistent over time (Winckler et al., 2007), and more frequent observation is needed to determine the

Table 4. Explanatory factors associated with Holstein cows with severe soiling on US free stall dairy farms $(\mathrm{n}=242)$

\begin{tabular}{lcccccc}
\hline Variable & Level & $\begin{array}{c}\text { Model } \\
\text { predicted } \%\end{array}$ & $\begin{array}{c}\text { Incidence } \\
\text { rate ratio }\end{array}$ & SE & Chi-squared & $P$-value \\
\hline Tail docking & Any & 8.8 & 1.555 & 0.304 Referent 5.09 & 0.024 \\
\multirow{2}{*}{ Region } & None & 5.7 & 0.539 & 0.137 Referent & \\
\multirow{2}{*}{ Dispersion } & West & 5.2 & 1.724 & 0.176 . & \\
\hline
\end{tabular}


Table 5. Explanatory factors associated with Holstein cows having severe hock lesions on US free stall dairy farms $(\mathrm{n}=196)$

\begin{tabular}{llccccr}
\hline \multirow{2}{*}{ Variable } & Level & $\begin{array}{c}\text { Model } \\
\text { predicted } \%\end{array}$ & $\begin{array}{c}\text { Incidence } \\
\text { rate ratio }\end{array}$ & SE & Chi-squared & $P$-value \\
\hline Stall base & Concrete & 1.8 & 2.118 & 0.312 & 5.77 & 0.016 \\
& Rubber mat & 2.3 & 2.789 & 1.095 & 6.83 & 0.009 \\
& Mattress & 2.3 & 2.685 & 0.906 & 8.56 & 0.009 \\
& Other & 0.8 & 0.900 & 0.309 & 0.09 & 0.760 \\
Region & Dirt & 0.8 & \multicolumn{4}{c}{ Referent } \\
& West & 0.5 & 0.124 & 0.055 & 21.91 & $<0.001$ \\
Stall bedding type & East & 4.1 & \multicolumn{4}{c}{ Referent } \\
& Straw & 1.9 & 2.596 & 0.882 & 7.88 & 0.005 \\
& Sawdust & 1.5 & 2.125 & 0.622 & 6.64 & 0.010 \\
& Dry or compost manure & 2.7 & 3.751 & 1.820 & 7.42 & 0.006 \\
Dispersion & Other & 1.1 & 1.464 & 0.595 & 0.88 & 0.348 \\
& Sand & 0.7 & \multicolumn{4}{c}{ Referent } \\
\end{tabular}

outcome associated with specific management practices or facility designs. Despite the methodological limitations of single-visit assessments, the dairy industry is facing increasing pressure to implement third party evaluation, likely in this format.

Several factors affect cow hygiene, including manure management (Magnusson et al., 2008), stall size (Zurbrigg et al., 2005), and bedding type (Fulwider et al., 2007; Norring et al., 2008). Improved cow hygiene reduced risk of exposure to pathogens (Schreiner and Ruegg, 2003; Munoz et al., 2008). In this study, tail docking and region were predictors of the proportion of cows that were severely soiled (score $=3$ ). Tail docking was the only management variable that remained in the final model; farms that docked tails had more severely soiled cows compared with farms that kept tails intact. Cow hygiene and subsequent improvements in udder health are often cited as a reason to dock tails, but research indicates that this practice does not improve hygiene or udder health in free stall systems (Tucker et al., 2001; Schreiner and Ruegg, 2002). Both the results of this survey and experimental evidence demonstrate that tail docking is not associated with cleaner cows in free stall barns.

Hock injuries are relatively common in dairy cows and can range from hair loss to open sores and inflammation of the tarsal joint. These injuries are influenced by both the dimensions and the quality of the lying area such that cows kept in open, deep-bedded systems rarely have severe hock lesions (Livesey et al., 2002; Barberg et al., 2007; Fulwider et al., 2007). In agreement with previous studies, we found that free stall farms using rubber mats or mattresses more likely had cows with severe hock lesions than farms with dirt bases (Weary and Taszkun, 2000; Wechsler et al., 2000; Fulwider et al., 2007). There is some disagreement about which specific types of mats or mattresses are more problematic (Tierney and Thomson, 2001; Livesey et al., 2002) and which bedding types work best (e.g., sand best in Weary and Taszkun, 2000; straw best in Keil et al., 2006); these discrepancies may be attributed to differences in how the bedding is managed and the dimensions of the stalls. In this study, farms using sand had the lowest percentage of severe hock lesions $(0.7 \%)$. Farms using manure solids had the highest percentage of severe hock lesions $(2.7 \%)$, and those using straw and sawdust as bedding were intermediate (1.5 and $1.9 \%$ cows with severe hock injuries, respectively). Based on a combination of experimental results and the current work, providing cows a well-bedded lying area and adequate space can help reduce the risk of hock injuries.

Region was evaluated as a predictor in all models and was associated with severe soiling and hock lesions. Farms in the east region had approximately twice as

Table 6. Explanatory factors associated with Holstein cows perching in stalls on US free stall dairy farms $(\mathrm{n}=177)$

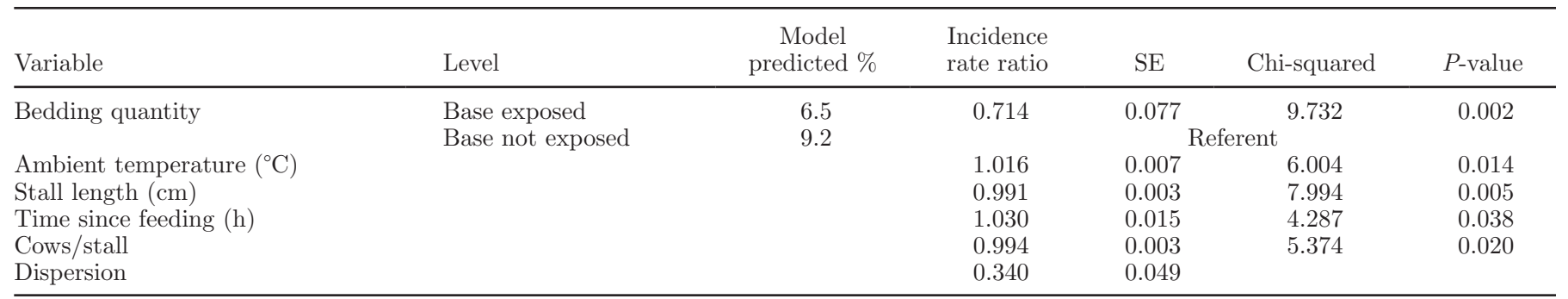


Table 7. Explanatory factors associated with Holstein cows standing fully in stalls on US free stall dairy farms $(\mathrm{n}=257)$

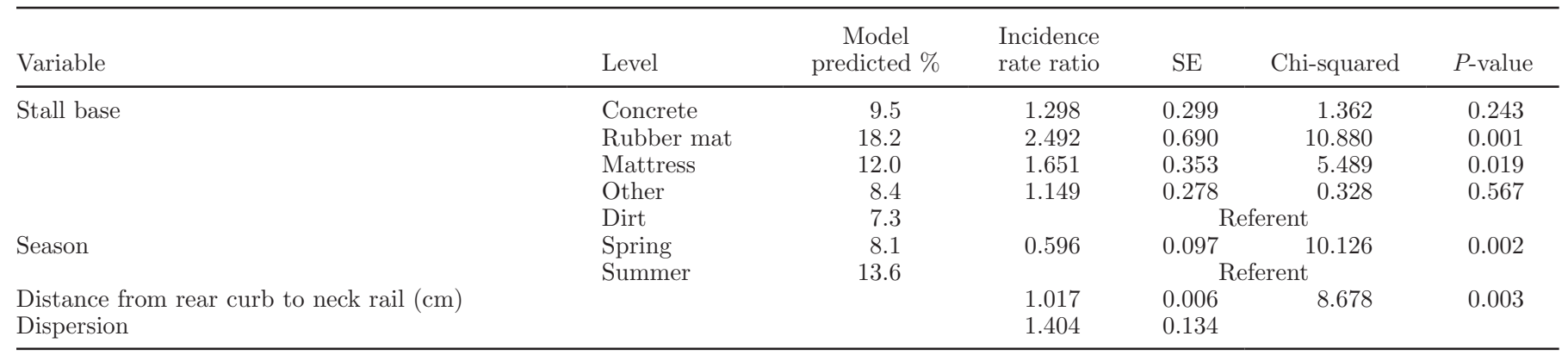

many severely soiled cows and 8 times more severe hock injuries compared with farms in the west region. Interestingly, the differences between regions were larger than differences explained by any single management factor. It is possible that region corresponds with environmental variation not measured or combinations of management factors not explored. Indeed, differences between region need to be interpreted with caution because the biological explanation for these differences is unclear and may be less meaningful than specific housing or management measures. Additional studies should be conducted to further explore the regional differences observed in this study.

More cows stood with only the front feet in shorter stalls; other research has shown that cows are more likely to perch and less likely to spend time standing fully in more a restrictive stall (e.g., narrow stalls: Tucker et al., 2004; stalls with more restrictive neck rail placement: Tucker et al., 2005; Fregonesi et al., 2009). Fewer cows were perching in stalls as stocking density increased, in agreement with Hill et al. (2009). Perching was more common as time since feeding increased (supporting Cook et al., 2005) and was more common at higher ambient temperatures, likely because cattle spend less time lying down in warm weather (Overton et al., 2002; Zähner et al., 2004).
Indeed, more cows stood fully in the stall and fewer were lying down in summer compared with spring. Cows were more likely to stand fully in the stall when the neck rail was less restrictive, in agreement with previous experimental work (Tucker et al., 2005; Bernardi et al., 2009; Fregonesi et al., 2009). Cows more likely stood fully in the stall if the base was categorized as a rubber mat or mattress. Cows spend more total time standing in stalls with mattresses compared with deepbedded options (Tucker et al., 2003; Cook et al., 2004, 2008). It is possible that the cows spend more time standing on mattresses or rubber mats because these surfaces provide a clean, nonconcrete option that is more comfortable than the alleyway. It is possible that cows stand more on mattresses or rubber mats because they are hesitant to lie down; Tucker and Weary (2004) found that cows spent more time perching in poorly bedded stalls, likely because these are less suitable for lying down upon.

Cows spend 0.5 to $3 \mathrm{~h}$ standing (Cook et al., 2004) and 5 to $20 \mathrm{~h}$ lying down (Ito et al., 2009) in free stalls. Several stall features influence variability in the percentage of cows lying. In this study, both bedding type and bedding amount influenced lying behavior. A lower percentage of cows were lying when stalls were bedded with organic materials (i.e., straw, sawdust, dry or

Table 8. Explanatory factors associated with Holstein cows lying in stalls on US free stall dairy farms $(\mathrm{n}=259)$

\begin{tabular}{|c|c|c|c|c|c|c|}
\hline Variable & Level & $\begin{array}{c}\text { Model } \\
\text { predicted \% }\end{array}$ & $\begin{array}{l}\text { Incidence } \\
\text { rate ratio }\end{array}$ & $\mathrm{SE}$ & Chi-squared & $P$-value \\
\hline \multirow[t]{5}{*}{ Stall bedding type } & Straw & 39.4 & 0.783 & 0.093 & 4.248 & 0.039 \\
\hline & Sawdust & 41.2 & 0.818 & 0.064 & 6.528 & 0.011 \\
\hline & Dry or compost manure & 37.8 & 0.750 & 0.095 & 5.199 & 0.023 \\
\hline & Other & 34.0 & 0.676 & 0.089 & 8.818 & 0.003 \\
\hline & Sand & 50.3 & \multicolumn{4}{|c|}{ Referent } \\
\hline Days since bedding added & & & 0.974 & 0.005 & 28.979 & 0.000 \\
\hline \multirow[t]{5}{*}{ Lunge barrier material } & Concrete & 40.9 & 1.030 & 0.142 & 0.045 & 0.832 \\
\hline & Wood & 31.3 & 0.787 & 0.069 & 7.598 & 0.006 \\
\hline & Cable & 51.9 & 1.305 & 0.199 & 3.049 & 0.081 \\
\hline & Other & 39.7 & 0.999 & 0.084 & 0.001 & 0.986 \\
\hline & None & 39.8 & \multicolumn{4}{|c|}{ Referent } \\
\hline \multirow[t]{2}{*}{ Season } & Spring & 44.0 & 1.201 & 0.080 & 7.505 & 0.006 \\
\hline & Summer & 36.7 & \multicolumn{4}{|c|}{ Referent } \\
\hline Dispersion & & & 0.242 & 0.024 & & \\
\hline
\end{tabular}


composted manure) compared with sand. Regardless of bedding type, more cows were lying in stalls that had been recently and well bedded, in agreement with experimental findings about the depth and distribution of sand (Drissler et al., 2005) and organic materials including straw and shavings (Tucker and Weary, 2004; Tucker et al., 2009). Finally, farms with wooden barriers at the front of the stall had a lower percentage of cows lying compared with farms without a lunge barrier. We are not aware of any reason why the material the barrier is constructed from should affect this behavior. It seems more likely that farms using this construction may have been using larger barriers or placing them in a way that disrupted lying behavior. Others report that lunge barriers are a risk factor for lameness (Dippel et al., 2009), highlighting the need for further experimental evaluation of this stall feature.

The use of a single time point sample to measure behavior is likely inadequate. At the time of this study, using a single time point between milkings was a commonly accepted method for assessing these behaviors (Cook et al., 2005). More recent research suggests that much more frequent sampling is required to generate accurate estimates of average herd lying times (recording 30 or more cows every 5 min for $72 \mathrm{~h}$; Mitlöhner et al., 2001; Ito et al., 2009). Similar work is still required to understand what type of sampling is appropriate for standing behavior.

\section{CONCLUSIONS}

Several management and housing design features influenced hygiene, hock injuries, and stall use in US free stall barns. Tail docking and region (east versus west) of the United States were associated with decreased hygiene. Providing cows with well-bedded, larger, and less obstructed free stalls improved stall use. Hock injuries were less common on farms that had dirt-based and sand-bedded stalls and were in the west. Results of this NAHMS survey are in agreement with many controlled studies and suggest that these experimental results can often be usefully extrapolated to on-farm conditions. Many of the factors associated with cow comfort measures are affected by farm management. These results provide the basis for specific recommendations of management changes that can increase cow comfort on free stall dairy farms.

\section{REFERENCES}

Barberg, A. E., M. I. Endres, J. A. Salfer, and J. K. Reneau. 2007. Performance and welfare of dairy cows in an alternative housing system in Minnesota. J. Dairy Sci. 90:1575-1583.

Bernardi, F., J. Fregonesi, C. Winckler, D. M. Veira, M. A. G. von Keyserlingk, and D. M. Weary. 2009. The stall-design paradox:
Neck rails increase lameness but improve udder and stall hygiene. J. Dairy Sci. 92:3074-3080.

Capdeville, J., and I. Veissier. 2001. A method of assessing welfare in loose housed dairy cows at farm level, focusing on animal observations. Acta Agric. Scand. Anim. Sci. 51:62-68.

Cook, N. B. 2007. A toolbox for assessing cow, udder and teat hygiene. Pages 31-43 in Proc. 46th Annu. Mtg. Natl. Mastitis Counc., San Antonio, TX. National Mastitis Council, Madison, WI.

Cook, N. B., T. B. Bennett, and K. V. Nordlund. 2004. Effect of free stall surface on daily activity patterns in dairy cows with relevance to lameness prevalence. J. Dairy Sci. 87:2912-2922.

Cook, N. B., T. B. Bennett, and K. V. Nordlund. 2005. Monitoring indices of cow comfort in free-stall-housed dairy herds. J. Dairy Sci. 88:3876-3885.

Cook, N. B., M. J. Marin, R. L. Mentink, T. B. Bennett, and M. J. Schaefer. 2008. Comfort zone-design free stalls: Do they influence the stall use behavior of lame cows? J. Dairy Sci. 91:4673-4678.

DeVries, T. J., and M. A. G. von Keyserlingk. 2005. Time of fresh feed delivery affects the feeding and lying patterns of dairy cows. J. Dairy Sci. 88:625-631.

Dippel, S., M. Dolezal, C. Brenninkmeyer, J. Brinkmann, S. March, U. Knierim, and C. Winckler. 2009. Risk factors for lameness in freestall-housed dairy cows across two breeds, farming systems, and countries. J. Dairy Sci. 92:5476-5486.

Drissler, M., M. Gaworski, C. B. Tucker, and D. M. Weary. 2005. Freestall maintenance: effects on lying behavior of dairy cattle. J. Dairy Sci. 88:2381-2387.

Fraser, D. 2006. Animal welfare assurance programs in food production: a framework for assessing the options. Anim. Welf. 15:93104.

Fregonesi, J. A., M. A. G. von Keyserlingk, C. B. Tucker, D. M. Veira, and D. M. Weary. 2009. Neck-rail position in the free stall affects standing behavior and udder and stall cleanliness. J. Dairy Sci. 92:1979-1985.

Fulwider, W. K., T. Grandin, D. J. Garrick, T. E. Engle, W. D. Lamm, N. L. Dalsted, and B. E. Rollin. 2007. Influence of free-stall base on tarsal joint lesions and hygiene in dairy cows. J. Dairy Sci. 90:3559-3566.

Hill, C. T., P. D. Krawczel, H. M. Dann, C. S. Ballard, R. C. Hovey, W. A. Falls, and R. J. Grant. 2009. Effect of stocking density on the short-term behavioural responses of dairy cows. Appl. Anim. Behav. Sci. 117:144-149.

Ito, K., D. M. Weary, and M. A. G. von Keyserlingk. 2009. Lying behavior: Assessing within- and between-herd variation in free-stallhoused dairy cows. J. Dairy Sci. 92:4412-4420.

Keil, N. M., T. U. Wiederkehr, K. Friedli, and B. Wechsler. 2006. Effects of frequency and duration of outdoor exercise on the prevalence of hock lesions in tied Swiss dairy cows. Prev. Vet. Med. 74:142-153.

Livesey, C. T., C. Marsh, J. A. Metcalf, and R. A. Laven. 2002. Hock injuries in cattle kept in straw yards or cubicles with rubber mats or mattresses. Vet. Rec. 150:677-679.

Magnusson, M., A. H. Herlin, and M. Ventorp. 2008. Effect of alley floor cleanliness on free-stall and udder hygiene. J. Dairy Sci. 91:3927-3930.

Main, D. C. J., H. R. Whay, L. E. Green, and A. J. F. Webster. 2003. Effect of the RSPCA Freedom Food scheme on the welfare of dairy cattle. Vet. Rec. 153:227-231.

Mench, J. A. 2008. Farm animal welfare in the USA: Farming practices, research, education, regulation, and assurance programs. Appl. Anim. Behav. Sci. 113:298-312.

Mitlöhner, F. M., J. L. Morrow-Tesch, S. C. Wilson, J. W. Dailey, and J. J. McGlone. 2001. Behavioral sampling techniques for feedlot cattle. J. Anim. Sci. 79:1189-1193.

Munoz, M. A., G. J. Bennett, C. Ahlstrom, H. M. Griffiths, Y. H. Schukken, and R. N. Zadoks. 2008. Cleanliness scores as indicator of Klebsiella exposure in dairy cows. J. Dairy Sci. 91:3908-3916.

Norring, M., E. Manninen, A. M. de Passille, J. Rushen, L. Munksgaard, and H. Saloniemi. 2008. Effects of sand and straw bedding on the lying behavior, cleanliness, and hoof and hock injuries of dairy cows. J. Dairy Sci. 91:570-576. 
Ofner, E., T. Amon, M. Lins, and B. Amon. 2003. Correlations between the results of animal welfare assessments by the TGI $35 \mathrm{~L}$ Austrian Animal Needs Index and health and behavioural parameters of cattle. Anim. Welf. 12:571-578.

Overton, M. W., W. M. Sischo, G. D. Temple, and D. A. Moore. 2002. Using time-lapse video photography to assess dairy cattle lying behavior in a free-stall barn. J. Dairy Sci. 85:2407-2413.

Schreiner, D. A., and P. L. Ruegg. 2002. Effects of tail docking on milk quality and cow cleanliness. J. Dairy Sci. 85:2503-2511.

Schreiner, D. A., and P. L. Ruegg. 2003. Relationship between udder and leg hygiene scores and subclinical mastitis. J. Dairy Sci. 86:3460-3465.

Stull, C. L., B. A. Reed, and S. L. Berry. 2005. A comparison of three animal welfare assessment programs on California dairies. J. Dairy Sci. 88:1595-1600.

Tierney, G., and R. D. Thomson. 2001. The role of finite-element analysis in predicting the injury-reduction potential of dairy cow cubicle synthetic beds. J. Agric. Eng. Res. 80:373-379.

Tucker, C. B., D. Fraser, and D. M. Weary. 2001. Tail docking dairy cattle: Effects on cow cleanliness and udder health. J. Dairy Sci. 84:84-87.

Tucker, C. B., and D. M. Weary. 2004. Bedding on geotextile mattresses: how much is needed to improve cow comfort? J. Dairy Sci. 87:2889-2895.

Tucker, C. B., D. M. Weary, and D. Fraser. 2003. Effects of three types of free-stall surfaces on preferences and stall usage by dairy cows. J. Dairy Sci. 86:521-529.

Tucker, C. B., D. M. Weary, and D. Fraser. 2004. Free-stall dimensions: effects on preference and stall usage. J. Dairy Sci. 87:1208-1216.
Tucker, C. B., D. M. Weary, and D. Fraser. 2005. Influence of neck-rail placement on free-stall preference, use, and cleanliness. J. Dairy Sci. 88:2730-2737.

Tucker, C. B., D. M. Weary, M. A. G. von Keyserlingk, and K. A. Beauchemin. 2009. Cow comfort in tie-stalls: Increased depth of shavings or straw bedding increases lying time. J. Dairy Sci. 92:2684-2690.

Weary, D. M., and I. Taszkun. 2000. Hock lesions and free-stall design. J. Dairy Sci. 83:697-702

Wechsler, B., J. Schaub, K. Friedli, and R. Hauser. 2000. Behaviour and leg injuries in dairy cows kept in cubicle systems with straw bedding or soft lying mats. Appl. Anim. Behav. Sci. 69:189-197.

Winckler, C., J. Brinkmann, and J. Glatz. 2007. Long-term consis tency of selected animal-related welfare parameters in dairy farms. Anim. Welf. 16:197-199.

Winckler, C., J. Capdeville, G. Gebresenbet, B. Horning, U. Roiha, M. Tosi, and S. Waiblinger. 2003. Selection of parameters for on-farm welfare-assessment protocols in cattle and buffalo. Anim. Welf. 12:619-624.

Zähner, M., L. Schrader, R. Hauser, M. Keck, W. Langhans, and B. Wechsler. 2004. The influence of climatic conditions on physiological and behavioural parameters in dairy cows kept in open stables. Anim. Sci. 78:139-147.

Zurbrigg, K., D. Kelton, N. Anderson, and S. Millman. 2005. Stall dimensions and the prevalence of lameness, injury, and cleanliness on 317 tie-stall dairy farms in Ontario. Can. Vet. J. 46:902-909. 